\title{
New technology for the recycling of aromatic amine waste products and salts of heavy metals into a multi-purpose non-toxic product
}

\author{
T. Yu. Grishchenko ${ }^{1} \&$ I. S. Maslennikova ${ }^{2}$ \\ ${ }^{1}$ National Research University Higher School of Economics (HSE), \\ Russia \\ ${ }^{2}$ Saint-Petersburg State University of Economics, Russia
}

\begin{abstract}
New technology for the repurposing of toxic industrial waste into non-toxic, multipurpose products is elaborated. The use of novel compounds for flotation separated potash ores, and as a mixture component for the neutralisation and lithification of domestic and industrial wastes and bottom sediments, are presented.

Keywords: toxic waste disposal, amino-complex compound, disposal of waste, flotation ore separation, bottom sediments, ecology.
\end{abstract}

\section{Introduction}

One of the major problems presented to natural and technical sciences by modern production methods is the creation of new technologies for the disposal of toxic industrial waste into multi-purpose, non-toxic products that meet certain technical requirements.

It is widely known that toxic industrial wastes pose a major environmental hazard. For example, the waste products of aromatic amines in Russia as a whole can be considered as a large-tonnage issue. Typically, semisolid aromatic amine waste products - in particular, diphenylamine - are taken to a landfill with periodic combustion taking place there. Liquid wastes from the manufacture of aniline and its derivatives as well as viscous waste monoethylaniline are discharged into slag collection points following acid waste treatment. At the same time, toxic amines evaporating from the waste pollute the atmosphere as well as, penetrating through the soil into groundwater, contaminating the water. Volley emissions of toxic 
water into open water cannot be excluded. The entire complex of harmful chemical substances released into the air and water basins from industrial emissions has an adverse effect on the soil fauna. During the combustion of resinous wastes in the production of aromatic amines and derivatives thereof, a wide range of organic compounds is formed in the air, the most carcinogenic of which are dioxins, toxic to the cells of living organisms. Vast areas of once fertile land are effectively turning into deserts due to salinisation and poisoning with pesticides.

With the aim of restoring natural resources, conservation and rehabilitation, it is necessary to create eco-friendly sustainable technologies for the utilisation of toxic industrial waste in multi-purpose non-toxic products.

\section{Principal problems of waste management in Russia}

\subsection{Russia and the global waste management context}

Russia produces more than 5 billion tonnes of waste annually. Of this, only $7-8 \%$ is recycled, and the rest - over $90 \%$ - of the waste is disposed of at unauthorised dumps and landfill sites [1]. These data are published in the July 2014 report by the Chairman of the Russian Public Chamber Commission on Ecology and Environmental Protection. The volume of accumulated waste in Russia has reached an unimaginable 90 billion tonnes. These wastes are disposed of in landfills occupying an area of 4 million hectares (slightly smaller than the area of the Netherlands), as well as in unauthorised dumps. Each year to these areas is added a further 400 thousand hectares of waste at unauthorised dumps. Figure 1 presents Federal Service for the Supervision of Natural Resources (Rosprirodnadzor) data on the dynamics of increasing waste in Russia [1].

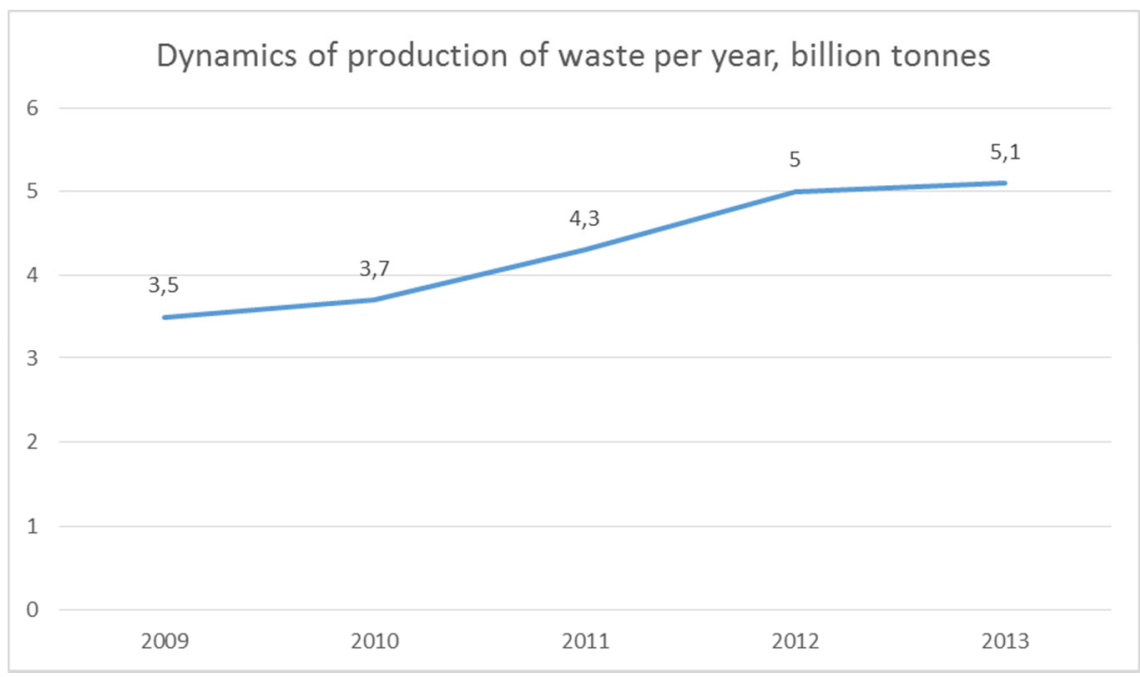

Figure 1: Dynamics of annual production of waste. 
From the perspective of inhabitants of Sweden, Russian behaviour, having failed to develop a proper environmental business model is unsustainable. The Swedes are world leaders in the re-utilisation of waste products. Furthermore, not satisfied with recycling their own waste products, the Swedes even import them from the United Kingdom, Norway and Ireland, boosting their earnings by providing recycling services. More than $98.5 \%$ of the waste produced in Sweden is reprocessed. The remaining $1.5 \%$ consists of materials that cannot be recycled in an environmentally friendly way (e.g. ceramics, asbestos, phosphorus). Only these wastes need to be disposed of. In Sweden, there are 31 recycling plants in operation and 57 organisations for the collection and sorting of waste. In Russia, the industry sector also seems impressively well-supported, with the data in Figure 1 showing a large amount of waste materials. According to the Russian Ministry of Natural Resources and Environment, in 2013 there were 40 waste incineration plants and 53 waste sorting complexes in operation [1]. However, the environmental and economic benefits from its activities in Russia are incomparably lower than in Sweden. Despite the organisational activity, a thriving recycling business environment is yet to materialise. It should be noted that the processing of waste by incineration is the lowest level of utilisation.

With the development of new technologies for waste disposal in Russia, the situation gets much more complicated. There are Russian developments; however, only a significant part reaches the stage of industrial implementation. There is still close to zero interest in recycling as a business. According to the Head of the Department of Water and Energy and Renewable Energy Research at the Institute of Energy Strategy (IES), there are two basic technologies for processing waste into electricity and heat. These consist of the processing of organic waste into biogas in special landfills, and incineration [2]. The first technology remains to be mastered in Russia. The second is faced by great difficulties, since it requires the separate collection of the various wastes (glass, metal, food waste, etc.). While the Swedish model for waste disposal works successfully, thanks to a well-functioning system of collecting already separated waste materials, in Russia, a culture of separating wastes for collection is virtually non-existent. There are separate experiments being set into motion at the instigation of the municipalities. For example, a project to separate waste collection launched in Moscow by the company "Sphera Ekologii" a few years ago more or less came to nothing. In May 2013, the authorities equipped a few points for separate waste collection in the Petrograd district of St. Petersburg. It was assumed that, if successful, such facilities would appear in other areas. However, after six months the experiment was wound up. The Deputy Chairman of the city's Environmental Committee reported the complete failure of the initiative, due to the fact that residents of the area apparently found it more convenient to simply throw away their garbage.

This may explain the significant difference between the Russian and Swedish approaches towards recycling. In Sweden, burial in landfills is the most expensive method of waste disposal. The authorities deliberately keep prices high to increase the cost-effectiveness of alternative means of recycling, which are more environmentally friendly, technologically advanced and, of course, expensive. Given these circumstances, the sorting and organisation of separate waste 
collection has become a profitable venture. Industrial companies do not carry the waste to landfills, but delivers it at zero cost to waste processing plants. There are also economic benefits to households. Having taken the decision to move to separate waste collection and concluded the relevant contract with the municipality, domestic residents enjoy significant discounts when paying for utility services [1].

\subsection{The status of waste management in Russia}

The Chairman of the Public Chamber Commission on Ecology and the Environment believes that "the main problem is the lack of a Russian market for waste management services. Much rests on the passing of relevant legislation. If the State should undertake the planned introduction of separation of waste, starting with various industrial enterprises, this would lead to a change in the mentality of the population in the long term". In Russia, unlike in Sweden, landfill is the cheapest way to dispose of waste. Low rates of landfill sites for the processing of solid domestic waste results in investment in alternative methods of waste processing being seen as meaningless and environmentally unjustified. There is nothing cheaper than burying waste in the ground: current rates vary from 200 to 600 rubles per cubic metre [1]. These are the approximate prices for landfill paid by organisations involved in the disposal of household wastes. The so-called "trash taxi" has become Russia's most competitive and vibrant segment (incidentally, the licensing of such services has already been abrogated for three years); meanwhile, in other segments of the industry there is a developmental hiatus. Alternative processing methods are generally developed only through the efforts of local administrative authorities, grants and subsidies. Depending on the type of material, the recycling of one tonne of waste in our country is approximately $4-8$ times more expensive than landfilling it. This would suggest the necessity to take a decision to raise tariffs for waste disposal by at least 4-5 times [1]. In 2013, the Ministry of Natural Resources and Environment submitted a draft of a comprehensive strategy for the treatment of solid waste until 2030, in which the emphasis was on a shift in priorities from landfill to recycling. The proposed innovations should primarily relate to the recycling of the energy component of household waste.

There should be a set of measures aimed at the gradual introduction of separate waste collection and incineration at waste incineration plants. In terms of new methods, the construction of landfills, capable of producing energy from landfill gas, has been mooted. However, the launch of market-based mechanisms is not presupposed. Apparently, there are serious concerns that this will give more of an impetus to illegal dumping than to the development of the industry. Their occurrence and spread can now only be controlled with great difficulty. According to the head of the organisation "Greenpeace Russia", compared to 16 thousand legal landfills in Russia at the present time, there are about 30 thousand unauthorised sites [1].

Consequently, in order to preserve and restore natural resources, it is urgently required to develop new technologies for the utilisation of toxic industrial waste in multiple applications. 


\section{New technology to improve the efficiency, safety, environmental utilisation and efficient disposal of toxic industrial waste}

\subsection{Synthesis of non-toxic amino-complex compounds from toxic industrial waste}

We propose a new technology to be used in recycling facilities for processing resinous wastes arising from the production of aromatic amines and their derivatives, as well as wastes from metallurgical industries such as chlorides and sulphates of copper, zinc, iron and other metals [3].

Instead of incineration or storage of wastes, we propose to utilise them for the synthesis of non-toxic, multi-purpose amino-complex compounds (ACC) [4].

The use of waste products for the synthesis of amino-complex compounds at chemical enterprises and in titanium production has the following advantages.

- Simultaneous one-step neutralisation of unused by-products from the production of ferrous metallurgy and aromatic amines.

- No secondary contamination of the environment.

- The feasibility of a combining process without solvent, catalyst or heating, as well as eliminating the synthesis of amino-complex compounds in commercial products.

- The simplicity of the apparatus for the synthesis of amino-complex compounds.

- The simplicity of the process (instability in the structures of wastes from the production of aromatic amines does not require a modification of the process parameters and does not lead to a deterioration in the quality of the resulting product).

ACC is a crystalline powder with granular inclusions of different colours depending on the cation; its melting point is not less than $120^{\circ} \mathrm{C}$.

ACC is stable in the air, does not become clumped during storage and may be contained without any special precautions for long periods of time.

The novelty of the developed industrial technology of extraction of ACC from toxic waste is protected by patents of the Russian Federation [5].

As an example, several methods of ACC production are introduced below.

Copper-aniline complex compound (CACC) $\mathrm{CuSO}_{4} \cdot 2 \mathrm{An}$ can be synthesised on an industrial scale; the straightforward technology of its derivation is as follows. Aniline is added to a $1.64 \%$ aqueous copper sulphate solution at room temperature and stirred; the molar ratio of copper sulphate to aniline is 1.5:2.0. A crystalline green deposit is precipitated as a consequence of the reaction. The resulting product is separated on a porous filter (such as a Büchner funnel) and dried in the open air. Wastes from chemical enterprises can be used for the manufacture of CACC. The resulting amino-complex compound is non-toxic (conclusion of the Leningrad Research Institute of Labour Hygiene and Occupational Diseases).

Copper-aniline complex compound $\mathrm{CuCl}_{2} \cdot 2 \mathrm{An}$ can be synthesised on an industrial scale with waste products from the Kemerovo aniline plant according to 
the following procedure. To a $1.0-3.4 \%$ aqueous aniline solution at room temperature is added the copper chloride and mixed at a molar ratio of copper chloride and aniline (1.3-1.7) : (1.7-2.0). A black fine crystalline product is formed, which is separated on a porous filter and dried in air.

The zinc-aniline complex compound $\mathrm{ZnCl}_{2} \cdot 2 \mathrm{An}$ can be synthesised from the waste products of chemical plants. At ambient temperature, an $80-90 \%$ aqueous solution of $\mathrm{ZnCl}_{2}$ and aniline is mixed at a molar ratio of zinc chloride to aniline of (1.6-1.8) : (1.8-2.1). A white fine crystalline product is formed, which is separated on a porous filter and dried in air.

The iron-aniline complex compound (ACC) $\mathrm{FeCl}_{2} \cdot 2 \mathrm{An}$ can be synthesised from waste products from the Berezniki chemical plant (residues following distillation of aniline) and Berezniki Titanium-Magnesium Works (solid titanium chloride production). Mixing the distillation residue following distillation of aniline and chlorides from solid titanium production is performed based on a molar ratio between $\mathrm{FeCl}_{2}$ and aniline of (1.7-2.0) : (1.5-1.7). The combination of components is carried out in a mixing tank. Upon completion of loading of the components they are stirred for 10-15 min. After stirring, the amino-complex compound forms in a cryptocrystalline state, which is removed and analysed for free amines. The product obtained should not contain free amines. The aminocomplex compound is transported and stored in plastic bags.

To provide a rationale for the legality of the introduction of new technology in connection with the utilisation of industrial toxic waste, a synthesis of ACC from pure products and the study of their physical and chemical properties had already been carried out.

A comparison of the results of ACC research by IR spectroscopy, X-ray, magnetic chemistry and electron paramagnetic resonance permitted their structure to be determined. The data obtained on the geometric structure of the investigated ACC were used to determine the type of hybrid orbitals of $\mathrm{Co}, \mathrm{Ni}, \mathrm{Cu}$ and $\mathrm{Zn}$ for the purpose of calculating the overlap integrals of the "metal-nitrogen" bonds. In addition to data on the geometric structure of the complexes, the results of quantum chemical calculations were also used $[6,7]$. A calculation of the overlap integrals between the hybrid orbitals of the metal and nitrogen was performed using the wave functions. The correlation analysis method demonstrated the sensitivity frequency of antisymmetric stretching vibrations of $\mathrm{NH}$ coordinated amines to the substitution position in the aromatic ring, the nature of the cation, anion salts and the presence of the naphthyl cycle [8].

\subsection{Use of amino-complex compounds in the economy}

Due to the diversity of their properties, amino-complex compounds are used in many areas of the economy. Some of these properties may be listed as follows.

\subsubsection{Amino-complex compounds - mixing components for the neutralisation and lithification of domestic and industrial waste and bottom sediments}

Amino-complex compounds can be used as a component for mixtures used to neutralise and lithify domestic industrial wastes and bottom sediments [9]. The 
invention relates to the production of artificial mineral mixtures intended for the disposal and lithification of liquid, viscous-plastic and solid domestic and industrial wastes and bottom sediments, sludges, etc., containing toxic compounds (salts of heavy metals, polycyclic aromatic hydrocarbons, petroleum products, synthetic surfactants, radionuclides, etc.). The technical result is an improvement in the mechanical quality of the obtained material.

The proposed compound has significant advantages over the following known compounds.

A commonly used mixture for sludge disposal and lithification of domestic and industrial effluents, containing the subsidiary filter substance of limestone or different slags and quicklime with $\mathrm{CaO}$ content $-82 \%$ in the amount of $60-80$ wt.\%. Pellets produced from the resulting interaction of the compound with slurries can be used in the cupola furnace charges or as a filler in the manufacture of concrete products. In addition, the resulting product can be stored in slag heaps as artificial ground. The disadvantages of this technology are the complexity of the sludge transformation mixture, the high cost of high quality lime used in very large quantities (60-80\% by weight), the need for belt filters and renewal of filterspecific adjuvant composition [8].

The mixture is also known for the neutralisation and lithification of sludges, as well as domestic and industrial wastes and bottom sediments, including fly ash, aluminosilicate wastes, lime, Portland cement and fine aggregates. The mixture ensures detoxification of sludges and wastes and their conversion into environmentally friendly soil, suitable for compact storage or for use in construction as a local material. This technological solution should be taken as a prototype of the present invention. The disadvantage of the established mixture is the fact that aluminium silicate solids have the property of high tack in the presence of moisture, making the process of mixing and compacting the mixture extremely difficult. Furthermore, the materials resulting from waste sludge and lithification have poor mechanical properties, in particular low strength and elasticity, which limits their use in construction [8].

The present invention provides a solution for the creation of a mixture for neutralisation and lithification of domestic and industrial wastes, as well as bottom sediments, which would have reduced tack, easily stirred with neutralised waste or sludges and well compacted, thus solving the problem of increasing the mechanical properties of the resulting material.

Per the present invention, this objective is attained due to the fact that the mixture for neutralisation and lithification of domestic and industrial wastes, as well as bottom sediments, including aluminosilicate solids, lime and Portland cement, additionally introduced aniline complex compounds of copper and/or iron and polypropylene fibre. Through the implementation of the distinguishing features of the invention, the mixture acquires important new properties.

Aniline complex compounds of copper and/or iron permit film polymerisation of water molecules around the particles of hydrophilic aluminosilicate solids thereby virtually eliminating tack in the mixture. The resulting mixture is blended well with the detoxified substrate, increasing the uniformity of the resulting material and its compressibility. 
Polypropylene fibre (fibrin) presents itself in a dispersed microfibrillar phase, which, when mixed with other ingredients adheres to a synthesised aluminosilicate binder; this interaction is responsible for the microstructure and homogenisation of the dispersion medium forming material.

Formula of invention: The mixture for neutralisation and lithification of domestic and industrial wastes, as well as bottom sediments, including aluminosilicate solids, lime and Portland cement, additionally introduced aniline complex compounds of copper and/or iron and polypropylene fibre with the following relationship of components, $\%$ :

Aluminosilicate solids $60-80$;

Lime 5-15;

Portland cement 10-20;

Aniline complex compounds of copper and/or iron 1-3;

Polypropylene fibre $2-3$.

\subsubsection{The use of amino-complex compounds for flotation desliming of potash ores}

Aniline complexes may find application in the flotation desliming of potash ores, consisting in treatment of the crushed ore with sludge reagent-collectors and flotation of the clay-carbonate and silicate slurries. Aniline complexes increase the efficiency of extraction and effectiveness of flotation of sludges, as well as reducing the cost of reagent-collectors.

The greatest difficulties in the flotation of potash ores arise from the presence of these clay-carbonate impurities which adsorb considerable quantities of reagent-collector onto themselves, thereby worsening the process of abietic flotation and raise the price of technology due to increased consumption of expensive and scarce reagent-collectors. In terms of collecting agents, claycarbonate slurries during flotation of potash ores use a combination of polyacrylamide and block copolymer of ethylene oxide and propylene on the basis of fatty acids. For the flotation of sludges a combination of polyacrylamide ethoxylated compounds is used, for example, alcohol oxy-leaded "oksanol-O-18". A disadvantage of this method is the necessary use of the expensive and scarce flotation reagent - polyacrylamide [8].

A widely used flotation clay-carbonate sludge from abietic collecting agents consists of a combination of polyacrylamide and ethoxylated fatty acids (EFA). This method consists in the fact that the bulk flotation slurry is carried out in the presence of collectors with the following expenditures: polyacrylamide (PAA) 1520 and EFA 30-40 g/t of ore. The disadvantages of this method are the low efficiency of the flotation sludges, low recovery of sludges, as well as the high cost and scarcity of polyacrylamide. The content of the sludge in the feed of the abietic flotation is reduced to $2 \%$ [8].

In order to improve the extraction efficiency and effective flotation of clay carbonate and silicate slurries as well as reducing the cost of collecting agents, crushed ore may be treated with ethoxylated fatty acids (EFA) and aniline complex compounds in a ratio of $4: 1$ (40 and $10 \mathrm{~g} / \mathrm{t}$ of ore, respectively) [10]. 
Aniline complex compounds have the ability to hydrophobise the surface of clay particles and to increase their flotation activity, which leads to increased recovery in foam products of sludges during flotation. In addition, aniline complexes permit a complete elimination of the use of expensive and scarce polyacrylamide. As aniline complex compounds are obtained from chemical production wastes, they are cheap reagents.

The proposed method of flotation desliming tested in the Galurgiya Research and Development Institute laboratory of sylvite Starobin deposit with the content (wt.\%): $\mathrm{KCl} 31.3$ and insoluble residue 3.0. The ground ore particle size of $-0.5+0 \mathrm{~mm}$ air-conditioned $2 \mathrm{~min}$ with sludge reagent-collectors: ethoxylated fatty acids, aniline complexes of zinc chloride $\left(\mathrm{ZnCl}_{2} 2 \cdot \mathrm{An}\right)$ or copper sulphate $\left(\mathrm{CuSO}_{4} 2 \cdot \mathrm{An}\right)$ at a dilution suspension of $\mathrm{F}: \mathrm{T}=2$. Boot sequence: aniline complex, then EFA.

Aniline complexes applied as solutions of acids: $\mathrm{ZnCl}_{2} 2 \cdot \mathrm{An}-18 \%$ solution in $2 \mathrm{~N} \mathrm{HCl} ; \mathrm{CuSO}_{4} \cdot \bullet \mathrm{An}-3.47 \%$ solution in $2 \mathrm{~N} \mathrm{H}_{2} \mathrm{SO}_{4}$.

Treated slurry was subjected to flotation reagents in the mechanical flotation machine slurry $\mathrm{F}$ at $\mathrm{T}=3$ for 3 minutes. For comparison, experiments were carried with the processing of a suspension in the traditional manner: polyacrylamide and ethoxylated fatty acids (15 and $40 \mathrm{~g} / \mathrm{t}$ of ore, respectively).

The results of sludge flotation with proposed reagents in the prior art method are shown in Table 1. As a result of the sludge flotation according to the method proposed, it is possible to increase the efficiency of sludge flotation by $13-15 \%$ and the extraction of impurities at $13 \%$ in the foam product, resulting in a reduction in the slime content of insoluble residue in the chamber product - the feed of subsequent abietic flotation is reduced from 2.05 to $1.42 \%$ compared to the conventional method. Analogously tested aniline complexes of zinc and copper present themselves as aniline complexes of iron.

Table 1: The use of amino complex compounds and sludge reagent-collectors.

\begin{tabular}{|c|c|c|c|c|c|c|c|c|c|}
\hline \multirow{3}{*}{ 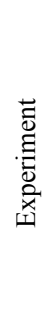 } & \multicolumn{5}{|c|}{ Reagent consumption, $g$ per tonne of ore } & \multirow{3}{*}{ 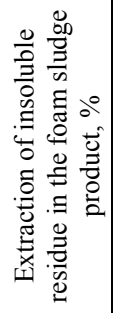 } & \multirow{3}{*}{ 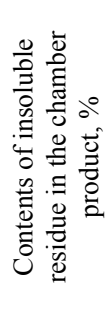 } & \multirow{3}{*}{ 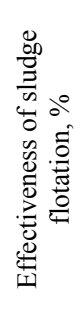 } & \multirow{3}{*}{ 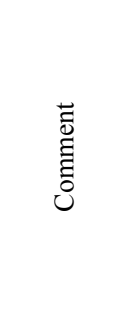 } \\
\hline & \multirow[b]{2}{*}{ 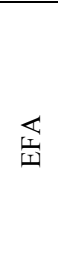 } & \multirow[b]{2}{*}{ 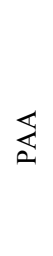 } & \multicolumn{2}{|c|}{$\begin{array}{l}\text { Aniline } \\
\text { complexes }\end{array}$} & \multirow{2}{*}{ 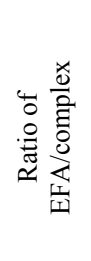 } & & & & \\
\hline & & & 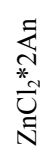 & 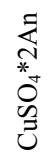 & & & & & \\
\hline 1 & 40 & 15 & - & - & - & 36.00 & 2.05 & 33.70 & $\begin{array}{l}\text { Known } \\
\text { method }\end{array}$ \\
\hline 2 & 40 & - & 10 & - & $4: 1$ & 51.95 & 1.42 & 46.60 & $\begin{array}{c}\text { Proposed } \\
\text { method }\end{array}$ \\
\hline 3 & 40 & - & - & 10 & $4: 1$ & 52.65 & 1.19 & 48.50 & $\begin{array}{c}\text { Proposed } \\
\text { method }\end{array}$ \\
\hline
\end{tabular}


Thus, the main advantage of the proposed method consists in improving sludge flotation and the application of a new sludge reagent-collector-aniline complexes derived from chemical production wastes instead of expensive and scarce polyacrylamide.

\section{Conclusions}

A new technology for the utilisation of toxic industrial wastes into non-toxic amino-complex compounds is achieved by means a simple and cost-effective synthesis. Amino-complex compounds maintain their properties during prolonged storage without special precautions packing and storage.

Analysis of an experimental batch amino-complex compound showed that it lacked free aniline. It can be assumed that in practice amino-complex compounds do not require special measures that differ from the general rules in order to comply with safety regulations. Working with amino-complex compounds does not cause danger in hot weather, since they only decompose at temperatures higher than $120^{\circ} \mathrm{C}$. Thus, working with amino-complex compounds is harmless.

Studies of the chemical and physico-chemical properties of the amino-complex compounds are not just theoretically interesting but are also of great practical importance, since they are widely used in practice. In particular, they are of interest for the management of some industrial processes, such as flotation desliming of potash ores; partial dehydration of colloidal gels of amphoteric hydroxides and clay minerals; the use of argillaceous rocks as raw materials for the ceramic industry. Using amino-complex compounds synthesised from toxic industrial wastes provides a clear ecological benefit.

\section{References}

[1] Shatalov, A., Can Russia Build Its "Rubbish" Power Following the Example of Sweden. Business Journal, 11, pp. 36-39, 2014.

[2] Platace, R. \& Adamovics, A., The Evaluation of Ash Contained in Grass Biomass used for Energy Production. WIT Transactions on Ecology and The Environment, 190(2), pp. 1057-1068, 2014.

[3] Maslennikova, I. S., Eronko, O. N. \& Grishchenko, T. Yu., Properties and use of amino-complex compounds synthesized from the industrial waste. Westnik IAELPS, 15(1), pp. 37-46, 2010.

[4] Maslennikova, I. S., Eronko, O. N. \& Grishchenko, T. Yu., The use of industrial waste for reliability improvement of building structures operation. Life Safety, New technologies: Moscow, 10, pp. 21-23, 2013.

[5] Maslennikova, I. S. \& Maslennikova, T. Yu., Method for Producing the Water-Binder for Dispersed Alumina Silicate Systems: RF patents No. 2041877, No. 2041880, No. 2041881, No. 2041882, No. 2041883, 1995.

[6] Demuynck, J., Etude théorique de la structure électronique de complexes de métaux de transition, Thèse: Sc. phys.: Strasbourg 1, 1972.

[7] Hillier, I. H.; Kendrick, J.; Mabb, F. E. \& Garner, C., An ab initio calculation of the bonding, excited states, and $g$ value of 
tetrachlorocobaltate (II), (CoCl4)2-. Journal of the American Chemical Society, 98(2), pp. 395-397, 1976.

[8] Maslennikova, I. S., New Technology to Increase the Reliability of Building Structures, SPbGIEU: St. Petersburg, pp. 79-108, 2012.

[9] Knatko, V. M., Knatko, M. V., Shcherbakov, E. V. \& Maslennikova, I. S., Mixture for the Neutralisation and Lithification of Household and Industrial Wastes, as well as Bottom Sediments: RF patent No. 2162068, 1999.

[10] Titkov, S. N., Maslennikova, I. S., Ryzova, M. M. \& Topina, N. A., Flotation Method for Desliming Potash Ores: SU patent No. 1347982, 1987. 